\title{
Adopting self-accreditation in response to the diversity of higher education: quality assurance in Taiwan and its impact on institutions
}

\author{
Karen Hui-Jung Chen ${ }^{1} \cdot$ Angela Yung-Chi Hou ${ }^{2}$
}

Received: 20 July 2015/Revised: 21 January 2016/Accepted: 22 January 2016/Published online: 30 January 2016

(c) Education Research Institute, Seoul National University, Seoul, Korea 2016

\begin{abstract}
In 2012, Taiwan implemented a dual-track quality assurance system comprising accreditation and selfaccreditation in higher education institutions. Self-accrediting institutions can accredit their programs without requiring approval from external quality assurance agencies. In contrast to other countries, the Ministry of Education of Taiwan authorized self-accrediting institutions to develop their own evaluation standards. This study investigated the institution-based accreditation standards and their implications on institutional internal quality assurance. Content analysis revealed that $37 \%$ of the indicators of self-accreditation were new and not used as review indicators in the original accreditation track. Two frequently added indicators were featured indicators and levels of internationalization. The results also indicated that institutions tend to structure their internal quality assurance systems uniquely. Three types of approaches for developing institution-based standards were identified: bottom-up, hybrid, and innovative approaches. Self-accreditation has benefited institutions committed to educational quality and pursuing excellence by enabling them to employ a fitness-for-purpose approach. The diversity of higher education and educational policy changes constitute
\end{abstract}

Karen Hui-Jung Chen

karen3117tw@gmail.com

Angela Yung-Chi Hou

035440@mail.fju.edu.tw

1 Department of Education, National Taipei University of Education, No. 134, Sec. 2, Heping E. Rd., Taipei 10671, Taiwan, ROC

2 Graduate Institute of Educational Leadership and Development, Fu-Jen Catholic University, No. 510, Zhongzheng Rd., New Taipei City 24205, Taiwan, ROC new challenges to higher education. Balancing between accountability and autonomy is critical for all stakeholders of higher education.

Keywords Accreditation · Self-accreditation · Quality assurance $\cdot$ Higher education

\section{Introduction}

As access to higher education has changed from elite to universal (Trow 2007), the rapid growth in universities has engendered attention to concerns of quality in higher education. With the increase in enrollments, the traditional forms of education quality control by governmental authorized institutional-based quality control procedures have been modified into external quality control. External quality assurance (EQA) bodies play a major role in maintaining the quality of higher education. However, to assure the integrity and autonomy of universities, EQA involves self-evaluation by universities and external peer review, thus balancing the views of internal quality assurance (IQA) and EQA.

Accreditation is one of the most widely used methods for EQA. Through the adoption of the same standards and minimum requirements for all universities, an institution or program can be evaluated by assessing an EQA body to determine whether its operation meets certain accreditation standards. However, the environment of higher education has changed considerably because of the following factors: demographic changes, declining public support, rapid development of information technology, and internationalization of higher education. The changing context has engendered a notable growth of different types of higher education institutions. It raised a concern that a single set 
of standards cannot be met by an increased diversity of higher education providers. Therefore, different QA arrangements are required for various types of institutions. The Council for Higher Education Accreditation (CHEA) in the USA proposed that QA should reflect diversity and be adopted accordingly, by modifying traditional QA approaches or developing novel QA approaches (Eaton 2015).

Several countries have responded to diversity by implementing self-accreditation to increase the flexibility of higher education, particularly in the Asia Pacific region. According to the International Network of Quality Assurance Agencies of Higher Education (INQAAHE), self-accreditation is defined as the practice of mature institutions to maintain IQA systems and be exempted from external accreditation of their programs and institutions (INQAAHE 2014). Self-accreditation was first implemented in the UK and has since been adopted by various countries including Hong Kong, Malaysia, and Australia (Wong 2013). These countries have given self-accreditation status to wellestablished and public higher education institutions under the assumption that institutions with a mature IQA system have the capacity to review their programs and ensure a high level of standards.

The Taiwanese government also adopted the self-accreditation approach in 2012. Studying the profile of Taiwan is important because the quality of Taiwan's higher education is globally recognized, and the total number of institutions is rapidly expanding. Regarding the quality, 9 universities in Taiwan were ranked among the top 400 universities worldwide and 12 universities were ranked among the top 100 universities in Asia, according to the QS World Universities Ranking 2015 (QS 2015). Regarding the quantity, Taiwan's higher education has expanded extremely rapidly during the past 30 years. The rate of tertiary education gross enrollment in Taiwan exceeded $50 \%$ in the 1990s and reached $84 \%$ in 2012, which are higher than those in other Asian countries (Chang 2015). To maintain the quality of the universities, the Ministry of Education (MOE) initiated a national QA agency, i.e., the Higher Education Evaluation and Accreditation Council of Taiwan (HEEACT), in 2006 to monitor the institutions to ensure their educational quality through accreditation. Up to date, two cycles of program accreditation and one cycle of institutional accreditation have been conducted. Most universities have since established their own QA units to maintain the educational quality.

Considering the rapid change in the environment of higher education, the MOE responded to the diversity by transforming the QA system from a single track (accreditation) into a dual track (accreditation and self-accreditation). A total of 34 universities were approved for implementing self-accreditation approaches, whereas other institutions maintained the conventional accreditation approach (MOE 2013). These self-accrediting universities can develop institution-based standards, thus constituting a novel approach for increasing QA variety. Hence, this study investigated the contents of the institution-based accreditation standards and the implications for the IQA of higher education institutions in Taiwan. Two research questions were addressed:

1. What are the differences between the accreditation standards developed by self-accrediting institutions and those developed by the national quality assurance agency, HEEACT?

2. How do self-accrediting institutions develop institution-based accreditation standards and what are the implications for institutional IQA?

\section{Literature review}

\section{Major elements of accreditation and self- accreditation}

Accreditation and self-accreditation involve different evaluation procedures, purposes, frameworks, and standards (Table 1).

\section{Procedure: $E Q A$ versus $I Q A$}

EQA and IQA play multiple roles in accreditation and selfaccreditation. EQA represents to the review activities performed by EQA bodies intended to demonstrate public accountability, whereas IQA is a QA process performed autonomously by institutions, and it emphasizes self-improvement (Vanhoof and Petegem 2007; Volkwein 2010). In accreditation, EQA bodies are responsible for developing predefined review standards and facilitating institutions and programs in complying with various requirements. Institutions provide evidence of their quality according to fixed standards and produce self-evaluation reports. Subsequently, the evidence is examined by a panel of experts during a visit to the institutions. The quality of institutions is ensured through internal and external procedures (Woodhouse 2013; Hoecht 2006). By contrast, self-accreditation, derived from accreditation, involves a mature institution conducting its IQA and being exempted from external accreditation. Self-accreditation relies more on institutional IQA than on EQA. A self-accrediting institution is fully authorized to invite external reviewers to inspect the deficiency of institutional or program quality. By establishing an institutional IQA system, an institution can stimulate institutional autonomy and enhance its 
Table 1 Major elements of accreditation and selfaccreditation

\begin{tabular}{lll}
\hline Items & Accreditation & Self-accreditation \\
\hline Standards & Same-for-all & Diversified and flexible \\
Framework & Fitness of purpose and fitness for purpose & Fitness for purpose \\
Purpose & Accountability and improvement & Self-improvement \\
Procedures & EQA and IQA & Predominantly IQA \\
\hline
\end{tabular}

capacity for managing quality concerns (Kinser 2011; INQAAHE 2014).

\section{Purpose: accountability versus improvement}

Accreditation standards comprise a single set of standards with limited room for institutions to effect changes. Through the assessment of an EQA body, an institution or program can be evaluated to determine whether its operation meets certain accreditation standards to ensure educational quality and accountability (Kells 1995; Rosa and Amaral 2007). In contrast to accreditation, self-accreditation enables individual institutions to determine how their performance is in accord with the institutional missions (Stensaker et al. 2011). Self-accreditation demonstrates a stronger improvement-oriented purpose. With knowledge of the specific property of its own institution, self-accreditation can be used to better implement institutional governance procedures for achieving self-improvement (Kinser 2011; Martin and Stella 2007).

\section{Framework: fitness of purpose versus fitness for purpose}

According to Martin and Stella (2007), two approaches of higher education can be distinguished: fitness for purpose and fitness of purpose. In the fitness-for-purpose approach, different institutions are assumed to exhibit dissimilar educational missions and goals. An institution can develop its own goals and can determine if the goals have been achieved. By contrast, the fitness-of-purpose approach concerns the level of purpose achieved. An accreditation framework is designed with both approaches. An institution first analyzes the institutional missions to develop program goals through the fitness-for-purpose approach. The mission statements are subsequently assessed by external reviewers through the fitness-of-purpose approach to determine their appropriateness (Dan $\varnothing$ and Stensaker 2007; Stensaker and Harvey 2006). However, the self-accreditation evaluation framework is principally associated with the fitness-for-purpose approach.

\section{Standards: same-for-all versus flexible}

The accreditation standards comprise a single set of standards with limited room for institutions to effect changes.
Through the assessment of EQA bodies, an institution or program can be evaluated to determine whether its operation meets certain accreditation standards (Hoecht 2006). However, in self-accreditation, institutions are given more authority to inspect their own educational quality according to their institutional contexts. Because of the substantial changes in higher education, institutions are discontent with this one-standard-for-all accreditation approach; therefore, novel QA methods are required to facilitate institutions in responding to the diversity (Eaton 2015; Halford et al. 2015).

\section{Self-accreditation in Australia, Hong Kong, and Malaysia}

Several countries worldwide have adopted self-accreditation. In Australia, both self-accrediting and non-self-accrediting approaches coexist, and a total of 44 public institutions have been granted self-accrediting status with autonomy to review their programs for accreditation. They are exempted from being audited by the Tertiary Education Quality and Standards Agency (TEQSA). In addition, 150 non-self-accrediting institutions are required to be evaluated by the TEQSA in 7-year cycles (TEQSA 2013).

Hong Kong's approach to self-accreditation and accreditation is similar to that of Australia. Self-accrediting status has been awarded to the eight public institutions funded by the governmental University Grants Committee (UGC). These institutions can accredit their own programs, but they still must be reviewed regularly by two external QA bodies, the Quality Assurance Council for degree programs and the Joint Quality Review Committee for subdegree programs. The results of the external reviews of self-accreditation are presented as recommendations, rather than as accreditation statuses (UGC 2014; Cheng and Leung 2014). The non-self-accrediting institutions are mostly private institutions, which must be regularly accredited by the Accreditation of Academic and Vocational Qualifications.

Malaysia has divided institutions into self-accrediting and non-self-accrediting types. Most institutions are nonself-accrediting and must be reviewed every 5 years by the Malaysian Qualifications Agency (MQA). The MQA has developed two types of review standards, namely the Code of Practice for Institutional Audit (COPIA) for institutional 
audit and the Code of Practice for Program Accreditation (COPPA) for program audit (MQA 2012). Until 2014, selfaccrediting status has been awarded to eight institutions by the Malaysian MOE, including four public institutions and four international branch campuses. Those self-accrediting institutions must apply the COPIA and COPPA standards in reviewing their programs and the institution. They can organize review panels for evaluating most programs, except for professional ones, such as medical or law programs (MQA 2014). However, the MQA regularly advises the institutions to ensure their educational quality.

\section{Self-accreditation in Taiwan}

Before 2012, all universities must be reviewed at both program and institutional levels through compulsory accreditation, according to Taiwan's MOE (MOE 2013). The national accreditor, HEEACT, was established for EQA purposes in 2005. The first cycle of program accreditation was completed in 2011, and the second cycle began in 2012. Five accreditation standards for program accreditation have been developed by the HEEACT: (1) objectives, core competence, and curriculum design; (2) teaching assessment and student learning evaluation; (3) student support and learning resources; (4) academic and professional achievement; and (5) performance of graduates and self-improvement mechanism. Each standard comprises several indicators. These five standards consist of 38 indicators (HEEACT 2013).

Since 2012, the QA system in Taiwan's higher education has been transformed from a single into a dual accreditation system. This new policy has engendered considerable impacts on higher education. Self-accrediting institutions autonomously develop standards for reviewing their programs, whereas the programs provided by nonself-accrediting universities must be accredited by the HEEACT (Author 2014). Self-accreditation is only applied in program accreditation and not at the institutional level (MOE 2013).

The new dual-track system features several changes compared with the previous one regarding purposes, procedures, and the use of results. First, the accreditation and self-accreditation tracks have distinct evaluation purposes. Taiwanese accreditation system is compulsory and has the purpose of accountability, whereas the new self-accreditation track aims at institutional improvement. Second, the two tracks feature distinct evaluation procedures. The accreditation track involves the application of fitness-ofpurpose and fitness-for-purpose approaches. An institution can establish its institutional mission adopting a fitness-forpurpose approach; subsequently, the mission statement is judged by external reviewers who determine the appropriateness by using a fitness-of-purpose approach. By contrast, the self-accreditation track entails adopting the fitness-for-purpose approach, enabling an institution to identify its strengths and determine review indicators. Third, the two tracks involve a distinct use of the accreditation results. According to the accreditation track, the MOE often uses the evaluation results as a reference to understand the quality of institutions for determining the numbers of student enrollments of the institution in the next year. Conversely, the results of self-accreditation are typically used by institutions for self-improvement.

\section{Research method}

The present research consists of two studies. The first study adopts content analysis to compare the accreditation standards and indicators developed by 28 self-accrediting institutions as well as those of the HEEACT. Content analysis can be applied to studying visually represented material such as documents and portfolios to determine what content means and what information is conveyed (Krippendorff 2013; Schreier 2012). The conducted content analysis enabled generating word-frequency lists according to two steps. First, the accreditation standards of the HEEACT were analyzed and fragmented on the basis of nouns and conjunctions. After the analysis of the 38 indicators, a coding frame was developed. For example, indicator "sufficient and qualified full-time and adjunct faculty" was fragmented into six parts in the coding scheme, as shown in Table 2: (1) sufficient full-time faculty, (2) qualified full-time faculty, (3) sufficient adjunct faculty, (4) both 1 and 2, (5) qualified adjunct faculty, and (6) both 3 and 4 . Next, the coding frame was applied to analyze the accreditation standards developed by the self-accrediting institutions.

Second, a rubric was constructed to enable scoring the similarity of review indicators developed by the HEEACT and institutions. Full credit was given in addition to two points if the content of the indicator developed by an institution was exactly the same or simply entailed combining separate items into a single item. One point was given if the content of the indicator developed by an institution was partially the same. No credit was given if the content of the standard was entirely different. The analysis was conducted by the first author and two researchers familiar with quality assurance in higher education; the results of the analysis were discussed with the second author. The two raters independently coded a random selection of the indicators of three institutions (approximately $10 \%$ of the 28 institutions) to estimate the interrater reliability. The agreement between the raters in the first time was 0.80 . To reach a more favorable consensus, the raters discussed the problems and defined each term more clearly. Subsequently, they randomly selected 
Table 2 Coding frame (partial)

\begin{tabular}{ll}
\hline Review indicators developed by the HEEACT & Codes for analysis \\
\hline 2-1. Sufficient qualified full-time and adjunct faculty & 1. Sufficient full-time faculty \\
& 2. Qualified full-time faculty \\
& 3. Both 1 and 2 \\
& 4. Sufficient adjunct faculty \\
& 5. Qualified adjunct faculty \\
& 6. Both 4 and 5 \\
\hline
\end{tabular}

the indicators of another three institutions, and the interrater reliability reached to 0.91 .

The second part is composed of a series of three case studies. Specifically, three universities were identified and studied mainly through document analysis to determine how their IQA mechanism to maintain their educational quality and how they developed the accreditation standards and indicators for self-accreditation. The analyzed documents include the institutional regulations of self-accreditation developed by the universities, institutional selfaccreditation reports and review comments available online, open speech of institutional administrators in selfaccreditation workshop that were conveyed by the institutional association for experience sharing, addresses of institutional administrators invited by the QA agency (HEEACT), and papers written by institutional staff.

The three universities were selected because they are high-performance and world-class universities ranked within the top 100 universities in Asia, according to the QS ranking (QS 2015). Each of them has a long history of IQA, and their performance levels have been recognized by being granted with the Top University Project in Taiwan. They vary in size, mission, and characteristics, which represent three categories, namely: small comprehensive, large comprehensive, and non-comprehensive, and they focus on specific academic areas. In particular, their case studies reflected the diversity of how universities define and implement strategic IQA approaches consistent with individual university missions, core value, and daily university operation. The three institutions selected are National Sun Yat-sen University (NSYSU), National Chengchi University (NCCU), and National Taiwan University (NTU). These case studies elaborate the conceptions of self-accreditation by giving institutions more autonomy to respond to the diversified environment of higher education.

\section{Results}

\section{Comparison of the review indicators}

HEEACT adopted five accreditation standards with 38 indicators. Through content analysis, it was determined that the average score of the similarity between HEEACT and the accrediting institutions was 1.26 (out of 2), implying that $63 \%$ of the indicators developed by the selfaccrediting institutions were similar to those of HEEACT.

The results of the comparison at the level of indicators revealed that the highest score of similarity was exhibited in "how to provide support for student learning" with an average score 1.92. Because the accreditation standards were developed by the self-accrediting universities in Taiwan, the accreditation standards expressed the objectives the institution wanted to accomplish in the short and long term (Garcia-Aracil and Palomares-Montero 2010; Kells 1995). This finding revealed that universities prioritized their support of student learning and teaching. The second frequently used theme at the level of indicators was "sufficient qualified full-time and adjunct faculty" with an average score of 1.73 , reflecting that the universities emphasized on the qualification of faculty members, which is one of the basic requirements of the MOE for establishing a program and must be assessed by the MOE or institution.

By contrast, the theme deleted most frequently was the "enrollment and quality of graduate studies" with an average score of 0.38 . One reason for this is connected to the history and context of the development of higher education in Taiwan. Higher education expanded quickly, and postgraduate education has been increasing considerably since the mid1990s. However, Taiwan's fertility rate is declining, and the job market is saturated with university graduates, especially doctorate degree holders (Chan and Lin 2015). Finding employment is becoming increasingly difficult for graduate students, which has caused challenges in recruiting graduate students and maintaining the quality of graduate studies. The second frequently deleted theme was "sufficient space and facilities to fulfill teaching and learning needs" with a score of 0.50. The Taipei Times (2012) revealed that universities in Taiwan are facing a financial challenge for their operation, and this is because the tuition fees have been unchanged for numerous years while the gap between revenue and spending widens. Ensuring adequate facilities has become a challenge for most Taiwanese universities. This demonstrated by the phenomena that half of the universities deleted this indicator to avoid evaluation. 
An emerging concern is that several institutions have developed new indicators for self-accreditation. On average, 9.43 new indicators have been added. Half of the 28 institutions have added fewer than five new indicators, and five of the institutions ( $18 \%$ ) have added no new indicators (Fig. 1). The most frequently added theme was the feature indicator that provides a measure of the performance of the unique features of institutions involving different missions and circumstances. In total, $36 \%$ of the self-accrediting institutions encouraged identifying the strengths and weaknesses of programs and listed those as feature indicators or standards for review. The second frequently added theme was the level of internationalization. In total, $33 \%$ of the self-accrediting institutions incorporated internationalization into the review indicators, for example through enhancing students' foreign language proficiency, deepening campus internationalization, developing the international capacity of faculty members, creating a bilingual campus environment, and funding employment of counselors for foreign students.

\section{Approaches of developing review standards from the cases}

Self-accrediting institutions with distinct histories, contexts, and missions may adopt various methods for maintaining their IQA system. The following three cases exemplify various types of approaches, namely bottom-up, hybrid, and innovative approaches, for developing institution-based standards.
Bottom-up approach

National Sun Yat-sen University (NSYSU) is a small comprehensive university with 9547 students that comprised 6 colleges, 43 degree programs, and 3 research centers. It has received grants for the Top University Project in Taiwan for 10 years. Moreover, it is ranked in the top 70 universities in Asia, according to the 2015 QS Asia ranking, and its EMBA courses were ranked second in Taiwan and 48th in the world (QS 2015).

The institution adopted a bottom-up approach to develop its educational missions and review standards. It first analyzed its strengths and weaknesses by using the strengthweakness-opportunity-threat method to develop the missions and review indicators at the program level (NSYSU 2014a); next, these missions and indicators were reorganized to form the goals and review indicators at the college and institutional levels (Lee 2014; HEEACT 2014). Eight review standards comprising 29 indicators were discerned (NSYSU 2014b). Compared with the indicators in the accreditation track, the indicators developed by the institution scored 0.64 for similarity and included 15 new indicators.

Considering the learning outcome as a driving force for improvement, the institution requested all departments to identify the learning competence at the program level and define educational effectiveness with clear, observable, and measurable learning outcomes. Adopting an evidencebased evaluation approach, administrators of each program had to provide direct or indirect evidence of student
Fig. 1 Distribution of newly added indicators

\author{
Number of \\ Institutions
}

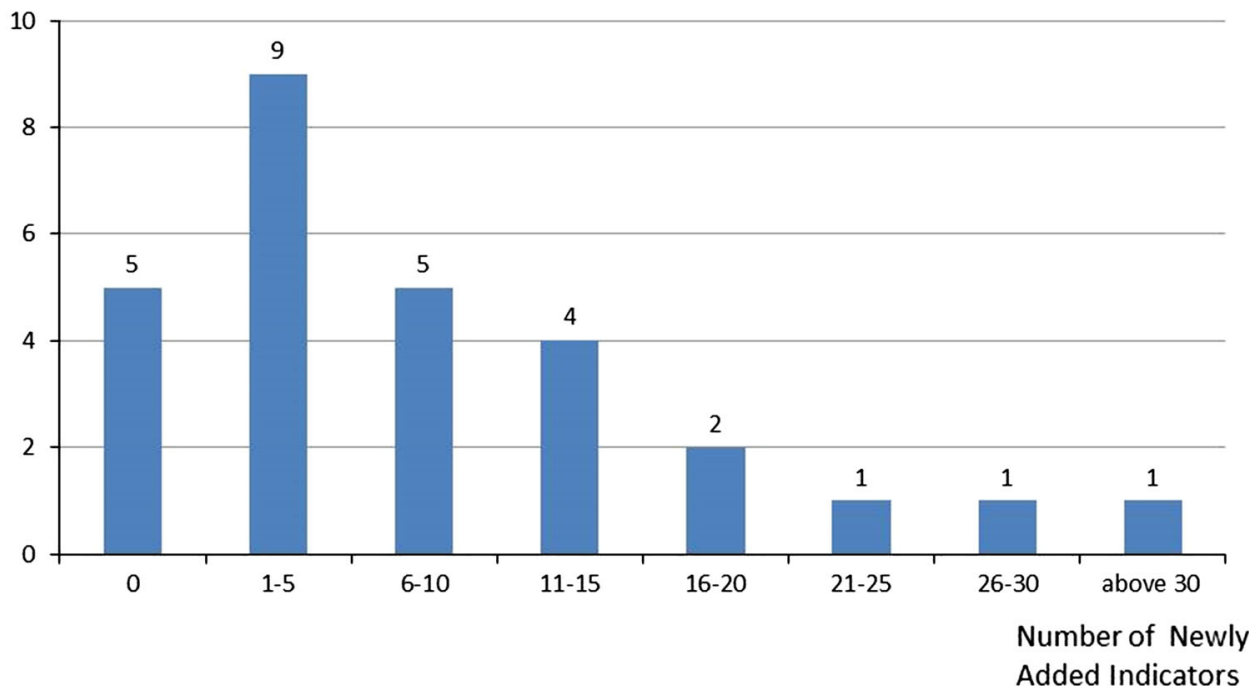


performance and learning supports (Lio 2013; NSYSU 2014c). Direct evidence included tests scores, student reports, and student portfolios, whereas indirect evidence included the survey of graduates and feedback from the employers of graduates (Lio 2012; Lee 2014). The approach focused not only on the evidence, but also on how the evidence was collected and how the program improved after the review. Through the bottom-up approach, the institution ensured that all departments were devoted to the review process from the beginning to the end.

\section{Hybrid approach}

National Chengchi University (NCCU) is a medium-sized university with approximately 15,000 students, 9 colleges, and 108 degree programs. It is extensively considered to have played a leading role in the humanities and social sciences in Taiwan. Over the past 10 years, it has received grants for the Top University Project in Taiwan.

The institution developed 7 accreditation standards and 31 indicators (NCCU 2015a), which scored 0.29 for similarity and included 29 new indicators. The similarity was lower than that of other self-accreditation institutions, and the number of new indicators was higher. According to the analysis, the low similarity was caused by differentiating the review standards into two distinct categories: common and feature standards (Lin 2014a; NCCU 2015b). Common standards were developed using a top-down approach decided in five administration offices, namely the academic, international affairs, research and development, student affairs, as well as finance offices. The top-down approach entailed a focus on the basic requirements for program operation and the alignment between departmental and institutional goals, such as the ratio of students to teachers (NCCU 2015c). By contrast, the feature standard developed using a bottom-up approach entailed beginning with the review indicators at the program level and subsequently transforming the results to form indicators for the college and institutional level (Lin 2014b; Jan 2015). Through collecting opinions on programs, an institution can effectively identify its features and create the corresponding indicators for review and fulfill the needs at the program, collegiate, and institutional levels.

\section{Innovative approach}

National Taiwan University (NTU) is a large comprehensive university with 33,000 students, 11 colleges, 54 departments, 109 graduate institutes, and 30 research centers. It is a leading research-intensive institution and is one of the most prestigious universities in Taiwan. Its high performance has been demonstrated by its consistent ranking in the top 30 universities in Asia, according to the QS Asia University ranking (QS 2015).
The institution had a long history of internal quality management and decided to adopt an evaluation framework that was distinct from that in the accreditation track, namely the context-input-process-product (CIPP) model (Juang 2013). Acknowledging the differences among programs, the institution authorized the development of unique indicators for each program for review under the CIPP framework. In addition, programs could be evaluated individually and jointly with other programs (Wu and Juang 2013). With limited restriction from the QA office, the staff administering programs was encouraged to identify features and provide unique educational services to fulfill various requirements.

The college of public health, for example, consisted of one department and four graduate institutes, and nine degree programs. Considering the similar educational mission and program features, the administrators of these nine programs decided to be jointly evaluated (Chen and Su 2013). To achieve international reputation, they decided to invite only international reviewers for an on-site visit (this is untypical in Taiwan). Inviting international reviewers is expensive, and the English capability of faculty and students must be adequate for conducting evaluation activities including writing self-evaluation reports and engaging in verbal communication.

According to this analysis, institutions of various sizes and contexts adopted unique approaches to develop their IQA systems (Table 3). According to the speech provided by the Dean of humanity of NCCU, reaching a consensus across departments was difficult because of the high number departments and the similar characteristic of the departments within the same college; therefore, this institution conducts its program self-accreditation at the college level, rather than the program or department levels (Lin 2014a, b). An easier approach for NCCU, a large university with 108 degree programs within 9 colleges, to manage its operation is to conduct its program accreditation at the college level rather than the program level, considering its numerous departments and institutes. However, NSYSU, a small university with 43 programs and 3 research centers in 6 colleges, administers its QA at the program level rather than the college level, by using a bottom-up approach. Hence, the various universities developed different types of IQA systems, revealing that the self-accreditation approach has decentralized the evaluation method.

\section{Discussion}

\section{Increasing flexibility of $\mathrm{QA}$ in response to institutional diversity}

The aforementioned analysis of institution-based standards reveals that $50 \%$ of the self-accrediting institutions in 
Table 3 Three different approaches for developing IQA

\begin{tabular}{|c|c|c|c|}
\hline Item & Bottom-up approach & Hybrid approach & Innovative approach \\
\hline $\begin{array}{l}\text { Approach for } \\
\text { developing IQA }\end{array}$ & $\begin{array}{l}\text { From program to college and } \\
\text { institution level }\end{array}$ & $\begin{array}{l}\text { From program and college to institution } \\
\text { level and vice versa }\end{array}$ & $\begin{array}{l}\text { From program and college to } \\
\text { institution level }\end{array}$ \\
\hline Institution type & Small institution (e.g., NSYSU) & Large institution (e.g., NCCU) & Large institution (e.g., NTU) \\
\hline Unit of accreditation & Program & College & College or program \\
\hline
\end{tabular}

Taiwan have developed new evaluation indicators. In particular, several prestigious institutions have adapted the original accreditation frame and developed new review standards by using innovative approaches. Shifting from same-for-all to diversified standards, different universities can have various means of evaluation. Therefore, the flexibility of accreditation was increased by implementing self-accreditation.

Accreditation has its limitation in the emerging diversified higher education era, in that this approach involves applying a single set of standards and review indicators. Whether uniform requirements suit various types of institution, and whether all institutions should provide comparable forms of evidence have been increasingly discussed (Martin and Stella 2007). Especially for prestigious institutions, threshold requirements for quality cannot fulfill the needs for pursuing excellence. Higher standards encourage competition between universities for recognition as excellent practices as well as enhance their profile and standing.

Because institutions differ substantially, various adjustments have been made. In the USA, the Higher Learning Commission (HLC) of the North Central Association (one of the six regional accreditors of higher education) revised the accreditation procedures in 2015. According to the newly updated resource guide of the HLC, institutions have been divided into three categories to enable applying various pathways for reaffirmation of accreditation: standard, the academic quality improvement program, and open pathway. Open pathway is a unique design enabling wellestablished institutions to plan and conduct improvement projects according to individual needs. Peer reviewers evaluate only the reports and recommend whether an institution has achieved the goals of quality assurance (HLC 2015). High institutional autonomy has been granted to institutions in an adjusted accreditation process. For example, the University of Chicago (a high-ranking university) has been approved to implement an open pathway to ensure high-level educational quality.

In Australia, Hong Kong, and Malaysia, an even higher degree of flexibility has been added to quality assurance through implementing self-accreditation, acknowledging the differences of institutional missions. According to the system of self-accrediting, institutions can conduct evaluations, invite reviewers to make suggestions, and selfmonitor improvements. Compared with the adjusted accreditation system, self-accreditation provides increased flexibility for institutions and relies more on institutional IQA.

Taiwan's adjusted self-accreditation system is at the end of the spectrum of making accreditation more flexible. In addition, the self-accrediting institutions in Taiwan are authorized to design the evaluation framework and standards. Therefore, unique standards have been developed by various types of institution. Through this approach, institutions have been given the autonomy to develop institutional features and pursue excellence.

\section{Key issues of institutional development of IQA}

\section{Quality driver: shifting from outsider to insider-driven quality control}

In the accreditation track, an EQA body inspects the quality of higher education on the basis of accountability and social responsibility. As a quality gatekeeper, the EQA body designs and operates the review process, including requesting the institution to submit a self-evaluation report, arranging on-site visits for reviews, determining accreditation results, and monitoring institutional improvement. The institution prepares the evidence in response to the accreditation standards developed by the EQA body.

In the self-accreditation track, the responsibility of QA is shifted from an EQA body to an institution itself. Instead of being monitored by an EQA body, self-accrediting institutions in Taiwan develop institution-based review standards, invite reviewers, and examine institutional improvement themselves. In general, a QA office administers these review activities in an institution. The aforementioned results show that a QA office can either be directly under presidential supervision or consist of a small team (2-3 persons) in the provost office. To reach a consensus, dialogs and communication among departments, colleges, and institution for good practices and self-improvements are increased. This encourages institutional faculty members to think about the institutional mission together and develop suitable standards for review. Rather 
than inspecting every detail of the review process, the EQA body inspects the design and operation of the institutional QA systems in terms of institutional self-regulation. The EQA body has changed its role from advocating and policing to facilitating and monitoring. The driving force of maintaining QA has been shifted from the outside (EQA body) to the inside (institution).

\section{Institutional diversity: various manners of pursuing excellence by using a fitness-for-purpose approach}

With globalized access to knowledge and the rapid technological development and innovation, the ability of higher education institutions to quickly respond to changes in the environment is a crucial factor for success (Knight 2004). Designing QA methods by using a fitness-for-purpose approach for a wide range of higher education institutions is pivotal. This study identified three types of model for developing institution-based standards and IQA systems. According to the fitness-for-purpose approach, self-accrediting institutions are granted increased autonomy for focusing on institutional development rather than responding to external requests. Through the establishment of specific evaluation frameworks and review standards, self-accreditation has become an effective instrument for achieving university excellence. Institutions can evaluate their performance and provide students with superior educational services.

The aforementioned results show that the level of internationalization is one of the most frequently added new indicators of self-accrediting institutions. To increase international competitiveness, several self-accrediting institutions have added internationalization as an indicator for review, including recruiting international students, promoting international exchange, and enhancing the international competitiveness of universities. In the pursuit of internationalization, several institutions have asked administrators of every program to invite international reviewers to obtain suggestions for improvement in a global context. Internationalization has been recognized as one of the means through which institutions connect their works globally (Hudzik 2015). By developing internationalization-related review indicators, institutions are progressively self-improving their programs toward comprehensive internationalization.

\section{Challenges: self-improvement enhancement or limited quality control}

Self-accreditation can enhance institutional self-improvement but also impede quality control. According to the aforementioned analysis, the indicators that institutions deleted were those that are difficult to achieve. For example, the most deleted indicator was "sufficient spaces and facilities for student learning," which is an essential requirement for any institution. Institutions might omit this indicator because of the high expenses associated with space and facilities; however, without sufficient academic infrastructure, teaching and learning can be ineffective and restricted. Another frequently deleted indicator was "the quality and quantity of graduate students," which is also crucial for institutions. With a low fertility rate and a saturated job market in Taiwan, institutions are facing the challenge of recruiting graduate students and maintaining the quality of graduate study. Therefore, various institutions have deleted this indicator to prevent inspection.

Giving autonomy to institutions may encourage institutional self-regulation and increase the development of diversity, but it might limit the quality control of higher education. An increasing number of countries have tried to make QA systems flexible to address diversity. Nevertheless, because universities are considered public entities, monitoring the quality of higher education is necessary. Balancing between institutional autonomy and accountability to ensure the quality of higher education remains a challenge in numerous countries.

\section{Conclusion}

The Taiwanese government has encouraged a diverse higher education system through implementing self-accreditation. This enabled the institutions with mature IQA systems to develop standards for review and perform institution-driven QA. Compared with the review indicators of the accreditation track, $37 \%$ of the institution-based indicators were newly developed. The two most added indicators were feature indicators and internationalization. The case studies revealed that history and campus culture were two leading factors determining the choice of models (e.g., bottom-up, hybrid, and innovative models).

The aforementioned example shows one of the approaches to adjusting quality assurance systems for diversified higher education. Diversity in higher education has become a global concern. In the accreditation track, review systems applying identical standards to all institutions can create barriers, impeding the ability of institutions to adapt to increasing diversity. Designing review models to fulfill the needs of a wide range of institutions with various missions is critical. The quality assurance of higher education must be adapted urgently to address increasing diversity and enable universities to fulfill a public service. Meanwhile, institutions should fulfill their mandates and honor their commitments to students and the public regarding satisfying the social needs in a fast-changing society. 
Accordingly, the accreditation system should be more flexible to provide increased space for diversity.

In Taiwan, higher education has progressed through creating a self-accreditation track for review. With a fitness-for-purpose approach and increased autonomy, institutions can concentrate on their institutional goals and long-term development through self-regulation. This transition to self-accreditation has implications for countries, especially those in the Asia Pacific region. As the economy grows in this region, higher education has been expanding quickly. Several Asian countries (e.g., Singapore and Korea) seek to become an education hub and pool of higher education talent by encouraging the growth of economic knowledge and importing branch campuses. The diversity of higher education and educational policy changes constitute new challenges to higher education. Responding to the fast changes in higher education with an appropriate quality assurance system has become critical to numerous governments, who must consider how to adjust QA systems and pursue excellence simultaneously. The balance of accountability and autonomy is critical for all stakeholders of higher education.

\section{References}

Author. (2014). A comparison study of the self-accreditation systems in Taiwan and other three countries/areas in the Asia-Pacific region. Higher Education Evaluation and Development, 8(1), 85-104.

Chan, S. J., \& Lin, L. W. (2015). Massification of higher education in Taiwan: Shifting pressure from admission to employment. Higher Education Policy, 28, 17-33.

Chang, D. F. (2015). Students in mass higher education: Effects of student engagement in Taiwan. In J. C. Shin, G. A. Postiglione, \& F. Huang (Eds.), Mass higher education development in East Asia: Strategy, quality, and challenges. New York: Springer.

Chen, W. J., \& Su, C. L. (2013). Inviting international reviews for self-accreditation. Evaluation Bimonthly, 45, 23-27.

Cheng, M. A., \& Leung, N. W. (2014). Quality assurance of non-local accounting programs conducted in Hong Kong. Higher Education Studies, 4(5), 47-61.

Danø, T., \& Stensaker, B. (2007). Still balancing improvement and accountability? Developments in external quality assurance in the Nordic countries 1996-2006. Quality in Higher Education, 13(1), 81-93.

Eaton, J. (2015). The emerging diversity of higher education and quality assurance. In Keynote speech of the 2015 conference of the international network of quality assurance agencies in higher education (INQAAHE 2015), March 31-April 3, Chicago, USA.

Garcia-Aracil, A., \& Palomares-Montero, D. (2010). Examining benchmark indicator systems for the evaluation of higher education institutions. Higher Education, 60(2), 217-234.

Halford, E., Jackson, S., \& McClaran, A. (2015). Diversity and its discontents: An examination of how UK higher education is responding to diversity, and the implications for quality assurance. Higher Education Evaluation and Development, 9(1), 1-15.

Higher Education Evaluation \& Accreditation Council of Taiwan (HEEACT). (2013). 2012 Annual report. Taipei, Taiwan: HEEACT.
Higher Education Evaluation and Accreditation Council of Taiwan (HEEACT). (2014). The quality assurance mechanism of a selfaccrediting institution. http://www.heeact.edu.tw/ct.asp?xItem= 15615\&ctNode=328\&mp=2. Accessed December 7, 2014.

Higher Learning Commission (HLC). (2015). Higher learning commission 2015 resource guide. http://download.hlcommis sion.org/ResourceGuide_2015_INF.pdf. Accessed 10 May 2015.

Hoecht, A. (2006). Quality assurance in UK higher education: Issues of trust, control, professional autonomy and accountability. Higher Education, 51(4), 541-563.

Hudzik, J. J. (2015). Comprehensive internationalization. London: Routledge.

INQAAHE. (2014). Analytic quality glossary, quality research international. http://www.qualityresearchinternational.com/glos sary/. Accessed January 15, 2015.

Jan, J. Y. (2015). A case study of self-accrediting university. Evaluation Bimonthly, 54, 47-49.

Juang, R. H. (2013). Self-accreditation mechanism of the National Taiwan University. In Presentation in HEEACT, November 20, 2013.

Kells, H. R. (1995). Self-study process (4th ed.). New York: Oryx Press.

Kinser, K. (2011). Multinational quality assurance. New Directions for Higher Educations, 155, 53-64.

Knight, J. (2004). Internationalization remodeled: Definition, approaches, and rationales. Journal of Studies in International Education, 8(1), 5-31.

Krippendorff, K. (2013). Content analysis: An introduction to its methodology (3rd ed.). Los Angeles: Sage.

Lee, Z. T. (2014). The self-accreditation mechanism of the National Sun Yet-San University. Presentation in the Center of Teaching and Learning Resources of the South Area in Taiwan, Febuary 3 , 2014.

Lin, C. P. (2014a). Case study of the self-accrediting institution. Presented in the Self-accreditation Workshop at the National Chiao Tung University, November 11, 2014 in Taiwan.

Lin, C. P. (2014b). Adopting self-accreditation: A case study of National Chengchi University College of Liberal Arts. Presentation in National Chiao Tung University, November 7, 2014.

Lio, M. C. (2012). Self-accreditation mechanism of the Nation Sun Yet-San University. In Invited speech in the National Cheng Kung University, November 29, 2012.

Lio, M. C. (2013). Learning outcome oriented self-accreditation. Evaluation Bimonthly, 44, 24-28.

Malaysia Qualification Agency (MQA). (2014). Self-accreditation. http://www.mqa.gov.my/. Accessed February 25, 2014.

Malaysia Qualifications Agency (MQA). (2012). 2011 Annual report. http://www.mqa.gov.my/portal2012/publications/reports/annual/ Laporan\%20Tahunan\%202011.pdf. Accessed December 22, 2014.

Martin, M., \& Stella, A. (2007). External quality assurance in higher education: Making choices. Paris, France: International Institute for Educational Planning (IIEP) UNESCO.

Ministry of Education, Taiwan (MOE). (2013). Self-accreditation regulation. http://edu.law.moe.gov.tw/LawContentDetails.aspx? $\mathrm{id}=\mathrm{GL} 000677 \&$ KeyWordHL $=\% \mathrm{E} 5 \% \mathrm{~A} 4 \% \mathrm{~A} 7 \% \mathrm{E} 5 \% \mathrm{AD} \% \mathrm{~B} 8 \%$ $\mathrm{E} 8 \% 87 \% \mathrm{AA} \% \mathrm{E} 6 \% 88 \% 91 \% \mathrm{E} 8 \% \mathrm{~A} 9 \% 95 \% \mathrm{E} 9 \% 91 \% 91 \% \mathrm{E} 7 \%$ B5\%90\%E6\%9E\%9C\&StyleType=1. Accessed April 20, 2014.

National Chengchi University Office of Research and Development (NCCU). (2015a). Self-accreditation mechanism and results for review. http://ord.nccu.edu.tw/service/super_pages.php?ID=book3/.

NCCU. (2015b). Self-accreditation regulation of the National Chengchi University. http://ord.nccu.edu.tw/files/archive/631_ e1db28e3.pdf.

NCCU. (2015c). Self-evaluation report of the College of Humanity of NCCU. http://ord.nccu.edu.tw/files/archive/697_a44cea5f.pdf. 
NSYSU. (2014a). Self-accreditation regulation of the Nation Sun YetSan University. http://tdc.oaa.nsysu.edu.tw/ktp/downloadCon tent/lawDownload/.

NSYSU. (2014b). Evaluation and indicators for self-evaluation of the Nation Sun Yet-San University. http://cola.tdc.nsysu.edu.tw/ktp/ evaluationContent/index/4.

NSYSU. (2014c). The self-accreditation framework of the Nation Sun Yet-San University. http://cola.tdc.nsysu.edu.tw/ktp/evaluation Content/index/2.

QS. (2015). QS World University Rankings 2015/16. http://www. topuniversities.com/university-rankings/world-university-rank ings $/ 2015 \#$ sorting $=$ rank + region $=+$ country $=+$ facult $y=+$ stars $=$ false + search $=$.

Rosa, M. J., \& Amaral, A. (2007). A Self-assessment of higher education institutions from the perspective of the EFQM excellence model. In D. F. Westerheijden, B. Stensaker, \& M. J. Rosa (Eds.), Quality assurance in higher education: Trends in regulation, translation and transformation. NY: Springer.

Schreier, M. (2012). Qualitative content analysis in practice. Los Angeles: Sage.

Stensaker, B., \& Harvey, L. (2006). Old wine in new bottles? A comparison of public and private accreditation schemes in higher education. Higher Education Policy, 19(1), 65-85.

Stensaker, B., Langfeldt, L., Harvey, L., Huisman, J., \& Westerheijden, D. (2011). An in-depth study on the impact of external quality assurance. Assessment \& Evaluation in Higher Education, 36(4), 465-478.

Taipei Times. (2012). University tuition fees to remain unchanged this year. Accessed on http://www.taipeitimes.com/News/front/ archives/2012/04/03/2003529372.
Tertiary Education Quality and Standards Agency (TEQSA). (2013). Self-accrediting authority. http://www.teqsa.gov.au/for-provi ders. Accessed December 20, 2014.

Trow, M. (2007). Reflections on the transition from elite to mass to universal access: Forms and phases of higher education in modern societies since WWII. In International handbook of higher education (pp. 243-280). Netherlands: Springer.

University Grants Committee (UGC). (2014). Quality assurance of UGC. http://www.ugc.edu.hk/eng/ugc/activity/qa/quality.htm. Accessed March 1, 2015.

Vanhoof, J., \& Petegem, V. P. (2007). Matching internal and external evaluation in an era of accountability and school development: Lessons from a Flemish perspective. Studies in Educational Evaluation, 33(2), 101-119.

Volkwein, J. F. (2010). The assessment context: Accreditation, accountability, and performance. New Directions for Institutional Research, 2010(S1), 3-12.

Wong, W. S. (2013). External quality assurance under a selfaccreditation system: Promoting and assessing internal quality assurance. In Paper presented at the 2013 Conference of INQAAHE, April 8-11, Taiwan.

Woodhouse, D. (2013). Global trends in quality assurance. Quality Approaches in Higher Education, 5(1), 3-7.

Wu, Y. H., \& Juang, R. H. (2013). Study of the self-accrediting mechanism in a university. Evaluation Bimonthly, 45, 18-22. 